\title{
Iot Disclosures in Leading European Companies
}

\author{
Enrique Bonsón ${ }^{1}$, David Perea², Michaela Bednárová ${ }^{3}$ \\ ${ }^{1,2}$ University of Huelva \\ +University Pablo de Olavide
}

\begin{abstract}
Internet of Things (IoT) is a technology that has spread across the whole society. It grants any object the ability to send data via provided communications networks. This implies certain guarantee of security and transparency of its use that companies should report on. Thus, this study examines an association between company characteristics and its voluntary IoT disclosure. The research sample consists of 329 companies listed on the Western European stock exchanges (including 13 countries). For the purposes of our study, voluntary disclosure in annual and sustainability reports (2018 and 2019) has been analyzed. The authors compiled 962 documents in total (annual and sustainability reports) that were later analyzed through an automated process using a code developed by them which allows to identify sentences including a keyword "Internet of Things (IoT)". The findings show that almost half of the companies disclosed aspects of the IoT (41.03\%) in their annual or sustainability report. However, the level to which the companies report on the IoT did not evolve that much during the observed period as the number of mentions in 2018 compared to 2019 was rather similar (around 1.60 mentions about IoT per document in both years). Lastly, we also found that telecommunication companies and large corporations (size measured by the logarithm of total assets) are more likely to provide disclosure on the IoT. However, the country where the company is headquartered does not seem to have any impact on the level of IoT disclosure.
\end{abstract}

Keywords: corporate reporting; IoT; European companies; telecommunications; voluntary disclosure 